\title{
REDES SOCIAIS, REDES TERRITORIAIS E MIGRAÇÕES
}

Ralfo Matos

Fernando Braga

\section{Resumo}

O paper apresenta os principais fluxos migratórios que circularam por localidades urbanas centrais do Brasil, entre 1980 e 2000. O controle das origens dos migrantes segundo movimentos de tipo centrífugos e centrípetos será efetuado, com vistas ao reconhecimento de características recentes dos migrantes internos capazes de impactar seletivamente os lugares- ponto da rede de localidades centrais, procurando indicar territorialidades emergentes. A avaliação da evolução e desempenho da rede de localidades no período, quanto à densidade e centralidade das localidades nas trocas migratórias se faz por meio de medidas da "Análise de Redes Sociais" aplicadas à migração interna, tomada como proxys de interação espacial. Cartogramas e gráficos resultantes exprimem os "pontos-manchas" da rede, nos quais a migração impactou mercados de trabalho de localidades periféricas, e que pode estar atuando como vetor de disseminação de inovações socioeconômicas. Tais inovações se associam a características dos migrantes obtidas pelo controle da procedência, ocupação e renda, com vistas ao reconhecimento de tipos áreas e movimentos populacionais capazes de impactar seletivamente localidades centrais

Palavras chave: Redes; Urbanização; Território; Migrações Internas.

- Prof. Adjunto do Departamento de Geografia do ICG/UFMG, Doutor em Demografia.

$\square$ Geógrafo, Mestrando do programa de pós-graduação em Geografia do IGC/UFMG. 


\section{1 - INTRODUÇÃO}

As chances de redução das desigualdades regionais, em um país com investimentos produtivos acumulados expressivamente ao longo do tempo, vinculam-se a uma série ampla de fatores. Dentre eles, a existência de uma base físico-territorial mais ou menos abrangente, dotada de articulações econômicas e sociais notáveis, pode ser uma prerrogativa só disponível há poucos países na atualidade. A presença de uma ampla rede de implantações tais como cidades, vias, indústrias e complexos produtivos em geral pode constituir-se em alternativa bastante cara aos formuladores de políticas públicas de corte regional. A rigor, pode-se dizer que oportunidades de empregos e investimentos em determinadas localidades atuam, durante um certo tempo, em um círculo virtuoso que alimenta o desenvolvimento econômico e a expansão da centralidade. Isto até que o ponto de saturação se estabelece e o que era vantagem passa a ser desvantagem. As deseconomias de aglomeração, embora difíceis de mensurar, são constrangimentos concretos que impõem sobre custos a pessoas e atividades em estruturas territoriais concentradas, que, historicamente, geraram riqueza, mas também desigualdades econômicas. Ou seja, grandes investimentos e estoques populacionais nos "cores” e esvaziamento e drenagem de recursos das periferias.

Se as regiões periféricas gradativamente se equipam, inclusive recebendo investimentos produtivos, e se, concomitantemente, as localidades centrais saturadas impõem crescentes sobre custos aos residentes (associados a transporte, moradia, poluição, saúde e stress), a fuga dos centros pode ser espontânea ou induzida por planos governamentais. Trabalhadores com os mesmos baixos salários em grandes cidades ou em cidades médias, muito provavelmente, preferem a segunda alternativa, em face da provável redução de custos de transporte e moradia. Se essa for de fato uma alternativa existente ou disponível aos formuladores de políticas públicas, caberia então indagar sobre a capacidade relativa de as periferias, enquanto base físico-territorial, representarem uma contrapartida consistente para a mitigação da pobreza e desigualdade socioespaciais.

É nesse âmbito que se coloca a pertinácia da reflexão sobre redes geográficas, e sobre as redes urbanas em particular, já que sua própria extensão e fisicalidade, bem como os laços que juntam pessoas, atividades e infraestruturas constituem um recurso estratégico para planejamento territorial dirigido a ampliação da equidade e redução das desigualdades. A ideia é que contar com a presença de uma rede urbana pouco fragmentada, densa e integrada constitui fator imprescindível à redução de disparidades regionais e econômicas. 


\section{2 - REDES URBANAS NO BRASIL}

O conceito de redes vem se tornando um caminho analítico para a compreensão de certos aspectos da organização dos centros urbanos e da forma como estes se articulam no território. As redes urbanas, em particular, fornecem importantes subsídios ao estudo das desigualdades regionais no Brasil, já que o conjunto das suas articulações pode indicar quais são os subespaços dotados de um maior número de conexões capazes de gerar economias de aglomeração suficientemente fortes para atrair fatores de desenvolvimento.

Estudos pioneiros sobre a formação do sistema urbano brasileiro, como os de DEFFONTAINES (1944) e MONBEIG (1954), já demonstravam como a origem da rede urbana no território estava diretamente relacionada com a expansão da movimentação interna da população. O povoamento dava início a um sistema de articulações que privilegiava determinados núcleos pólos, que deram origem a grandes áreas metropolitanas e cidades dotadas de alto poder de influência, a exemplo de São Paulo e Manaus.

O crescimento dos centros urbanos, no entanto, parecia não ser capaz de alterar significativamente o caráter concentrador da ocupação do território brasileiro. A especialização funcional das cidades traçava os aspectos mais característicos da rede urbana: fragmentação $\boldsymbol{e}$ descontinuidades, que geravam forte concentração dos fatores de desenvolvimento, os quais foram determinantes na expansão da indústria (GEIGER, 1963).

A concentração da população em poucas localidades polarizava as atividades econômicas e fazia com que os movimentos migratórios de maior porte se limitassem a poucas áreas de destino, característica que se manteve durante várias décadas do século XX. A partir dos anos 70, no entanto, um processo de descompressão do território começa a ganhar espaço, incentivado por iniciativas governamentais orientadas pela busca de maior equidade regional (AMORIM e SERRA, 2001). Desde então multiplicaram-se os centros urbanos de porte intermediário, que cooperam na redução da polarização das grandes metrópoles. Essa expansão se dá na medida em que os fatores de desenvolvimento, principalmente aqueles relacionados à desconcentração das atividades industriais, antes concentrados em localidades específicas, espraiam-se por áreas mais abrangentes (CORRÊA, 1994; SINGER, 1985; SANTOS, 1993; BAENINGER, 2000; AMORIM e SERRA, 2001).

Desta maneira novos subespaços foram criados, refletindo as dinâmicas econômicas e demográficas das últimas décadas. A mobilidade espacial, ao intensificar-se, estabelece uma nova redivisão social do trabalho, em função da proliferação de unidades de produção e comércio fora dos eixos de crescimento tradicionais (SANTOS, 1993).

Estudos recentes demonstram que o processo de urbanização no Brasil está em plena metamorfose, tanto em função das inovações técnicas introduzidas pela Globalização como também por características estruturais da evolução das redes urbanas, que, guardadas as 
especificidades dos processos históricos subjacentes e características físicas dos locais, podem ser observadas em grande parte das áreas urbanas do mundo de hoje (CORREA, 1994 e 1997; CLARK, 1982; BRADFORD e KENT, 1977).

Nos estudos sobre redes urbanas, fica evidente a relação estrita entre a aglomeração populacional e a existência de fatores econômicos diversos, que fazem aumentar a centralidade dos pontos mais dinâmicos, tornando-os pólos de atração para diversos fluxos que constroem a força das redes. Dentre esses fluxos as migrações internas têm especial importância, devido à capacidade do imigrante de levar consigo uma série de elementos indispensáveis à expansão dos centros urbanos como força de trabalho, conhecimento, capital, consumo, etc. (MATOS, 2002; MATOS e BRAGA, 2002).

Grande parte dos estudos sobre a migração interna se utilizam dos fatores de expulsão e atração da população como explicação teórica dos fluxos migratórios. Tais teorias consideram que as desigualdades regionais provocadas pelo movimento do capital, de acordo com cada processo histórico, podem impulsionar alguns indivíduos a buscar melhores condições de vida em outras áreas (SINGER, 1985).

Outros estudos que relacionam migração e urbanização, no entanto, divergem da ideia de que o ato de migrar reduz-se apenas a uma procura por melhores condições de vida. Dados recentes indicam que os fluxos migratórios também são um vetor de desenvolvimento, já que o imigrante pode contribuir positivamente nas localidades de destino. Isso se deve, em boa parte, a alteração nos padrões de movimento observados nos últimos anos, nos quais os migrantes de origem urbana são amplamente predominantes no total de migrantes, testemunhando o fato simples de que o Brasil se tornou amplamente urbanizado há pelo menos 20 anos. Essa alteração influi também no perfil dos imigrantes, porquanto tornaram-se mais experientes, mais informados e preparados para o emprego (MATOS, 2002). Os novos padrões migratórios observados desde a década de 80 indicam tanto uma reestruturação das redes urbanas, como uma transformação no perfil dos imigrantes que acompanha o recente processo de desconcentração espacial (SANTOS, 1993; PACHECO e PATARRA, 1998; BAENINGER 2000; ANDRADE e SERRA, 2001; AMORIM e SERRA, 2001; CUNHA, 2001).

Muitas questões essenciais ficam sem resposta no conjunto das teorias migratórias que atribuem o movimento, ora a uma decisão pessoal, ora a um reflexo das determinações do sistema econômico. Entre elas, duas questões básicas se colocam: "por que alguém se torna um migrante? Por que entre pessoas que estão submetidas aos efeitos das mesmas estruturas econômicas e sociais algumas migram e outras não?" Em função destas e outras questões, estudos recentes sobre os movimentos migratórios vêm considerando um conjunto complexo e dinâmico de elementos econômicos, sociais e estruturais, expressos nas redes sociais na migração(FUSCO, 2000; FAZITO, 2002; SOARES, 2002).

As redes sociais são fundamentalmente o meio pelo qual os sistemas migratórios se 
processam. As analises devem considerar o migrante não somente por seus atributos pessoais ou intenções individuais, mas sim como uma entidade dotada de relações que se conecta a outros conjuntos definidos por laços de parentesco, amizade, conhecimento, trabalho. Nesta perspectiva, os movimentos populacionais são, também, a expressão das possibilidades criadas por um conjunto de relações nas quais o indivíduo se insere (SOARES, 2002).

Os motivos que originam um determinado movimento podem estar associados à transformações estruturais nas sociedades, no entanto, a continuidade da migração provavelmente está mais relacionada a laços estabelecidos entre locais de origem e destino, que vão conferir estabilidade aos fluxos contínuos entre duas ou mais localidades. As redes sociais, assim, não são elaboradas no movimento migratório, mas transformadas por ele na medida em que se reforçam as conexões existentes entre o migrante e outros atores da sociedade (SOARES, 2002).

As redes sociais podem ser compreendidas então, como o conjunto de pessoas, organizações ou instituições sociais que estão conectadas por algum tipo de relação, podendo inclusive se sobrepor inúmeras vezes dentro de um sistema de relações. As redes migratórias seriam, então, uma espécie de rede social, precedida por outras redes que se adaptam ao objetivo de migrar, como as relações de parentesco, amizade, trabalho, etc. (SOARES, 2002; FAZITO, 2002).

Desta maneira os fluxos migratórios internos a rede urbana brasileira podem ser compreendidos segundo esta perspectiva de análise, na qual as localidades são os atores conectados por laços gerados pela migração, formando uma rede social que contém vários níveis de relações estabelecidas pelos imigrantes. Essa concepção permite trabalhar sobre alguns princípios básicos, como enumera SOARES (2002):

“i) os atores e suas ações são analisadas Inter dependentemente (violação do pressuposto de independência estatística); ii) os laços relacionais ou conexões entre atores são canais de transferência de recursos (materiais ou simbólicos); iii) os modelos de rede concentramse sobre as perspectivas individuais (micro) do ambiente estruturado (macro) e sobre a maneira pela qual esse ambiente oferece oportunidades e promove, ao mesmo tempo, constrangimentos estruturais sobre os indivíduos (princípio da circularidade e efeitos emergentes); iv) os modelos de rede conceituam estruturas (sociais, econômicas, políticas, demográficas, etc.) como padrões duráveis de relações entre atores".

Essa forma de tratamento das redes migratórias, ao evidenciar os laços entre imigrantes, pode contribuir para os estudos de redes urbanas, já que as redes sociais presentes na migração integram o conjunto das interações espaciais que compõem os sistemas de cidades. Evidentemente, quanto mais relações entre centros urbanos forem desveladas, mais consistentes tornam-se os modelos teóricos explicativos para as redes de localidades centrais. As conexões presentes nas localidades de origem e destino podem alocar o imigrante mais rapidamente no mercado de trabalho, principalmente ao se considerar as redes sociais podem selecionar melhores níveis de qualificação. Assim, a compreensão da contribuição dos imigrantes para a evolução 
da rede urbana brasileira pode ser enriquecida na consideração dos padrões relacionais expressos nas redes sociais da migração.

\section{3 - REDE URBANA BRASILEIRA E MIGRAÇÕES INTERNAS}

Aspecto essencial da civilização urbana, a aglomeração populacional guarda em si a reserva material necessária à evolução e reprodução dos elementos mais importantes das cidades. Assim, é possível que os locais de maior adensamento humano coincidam com os centros mais bem estruturados nas suas funções urbanas, já que a maior aglomeração de mão-de- obra reflete aspectos do adensamento produtivo e traduz a criação de atividades de natureza diversa. É de se esperar que as localidades que polarizam a rede urbana de um país de grande extensão como o Brasil podem ser identificadas, então, a partir da concentração populacional, aliada à expressividade regional da sua população urbana.

As ligações entre essas cidades podem iniciar o esboço de uma rede de localidades, que congregue os centros mais importantes do país, sendo cada um deles um ponto nódulo. Estes nós se articulam regionalmente com os municípios próximos e estabelecem relações com outras cidades, mais afastadas das grandes metrópoles, indicando os novos caminhos da urbanização no país e desenhando o caminho do processo de desconcentração espacial da população.

O presente estudo considera um conjunto de 165 localidades urbanas selecionadas a partir de 5 critérios que identificam a existência de ligações materiais entre os pontos, bem como as localidades de maior peso populacional nos contextos regionais. Os critérios, aplicados para os montantes populacionais em 1991, consideram que: i)Todo ponto da rede pressupõe a existência de articulações viárias (transportes rodoviário, ferroviário ou hidroviário permanente);

ii) Nove pontos correspondem as Regiões Metropolitanas oficiais, originalmente definidas por decreto/lei de 1973 (Regiões metropolitanas de São Paulo, Rio de Janeiro, Belo Horizonte, Porto Alegre, Salvador, Recife, Fortaleza, Curitiba e Belém). Cada região metropolitana comparece, na rede urbana, como um nódulo de primeira ordem; iii) Município com população urbana superior a 100 mil habitantes em 1991, que traduziriam os pontos da rede relativos às chamadas Cidades Médias; iv) Município cuja população urbana representasse mais de 3\% da população urbana do respectivo estado; v) Consideração de casos de macrocefalia urbana no estado do Amazonas, a partir da exclusão de Manaus da população total do estado e recalculando-se a proporção percentual dos demais municípios frente ao novo total, filtrando os casos de população urbana superior a $3 \%$ da população urbana do estado. Com isso pontos de rede dentrítica ganham visibilidade. 
As localidades selecionadas e suas articulações viárias podem ser observadas na Figura 1, que traz também a distribuição da população migrante nos anos de 1980 e $2000^{1}$, além dos valores de crescimento populacional no período. Os mapas mostram que, de uma forma geral, recaiu a participação dos migrantes no total da população das localidades. De fato, muitos processos migratórios que marcaram, principalmente, a metade do último século não mais ocorre com a mesma intensidade, e o aumento dos contingentes populacionais de todos os municípios ${ }^{2}$ reduz ainda mais a expressividade desta população.

\footnotetext{
${ }^{1}$ Em função da exclusão, no censo de 2000, das variáveis de migração de última etapa, o grupo de migrantes de 1980 e 2000 apresentam diferenças com relação às procedências: Os imigrantes de 1980 (ultima etapa) são os indivíduos que realizaram mudança de residência no período $1975-1980$ e a sua procedência corresponde ao último município no qual fixou residência antes da data do censo. Em 2000 os imigrantes (data fixa) são os indivíduos que realizaram mudança de residência entre o período de 1995-2000 e a sua procedência corresponde ao município em que residia no dia 31 de julho de 1995. Esta diferença faz com que em 2000 sejam excluídos dois grupos populacionais inclusos na definição de 1980: os residentes no mesmo município cinco anos antes, mas que efetuaram alguma mudança de residência no período e também todos os não-nascidos há cinco anos antes da data do censo.

2 As localidades da rede totalizavam 57.373.889 habitantes em 1980, já em 2000 a população total sobe para 86.588.373. Devido ao fato de que, em 1980, oito das 165 localidades ainda não eram municípios emancipados, a rede apresenta, nesta data, somente 157 pontos. Os municípios excluídos são: Jaru, Outro Preto do Oeste, Rolim de Moura (em Rondônia); Tabatinga (no Amazonas); Mucajai (em Roraima); Laranjal do Jari, Santana (no Amapá); e Palmas (em Tocantins).
} 
Figura 1

Participação dos imigrantes e crescimento urbano nas população total das localidades da rede
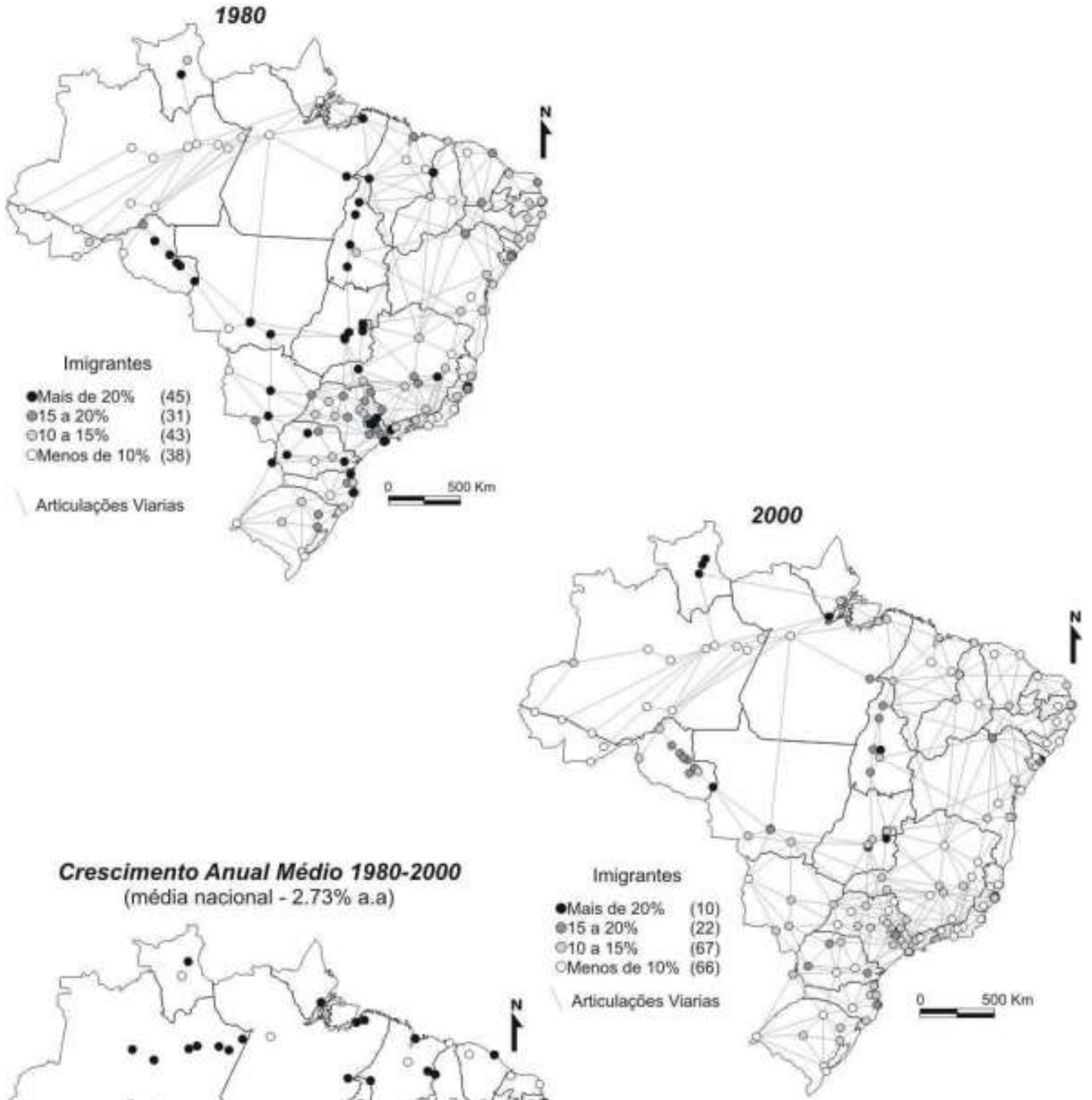

Crescimento Anual Médio 1980-2000 (média nacional $-2.73 \%$ a.a)

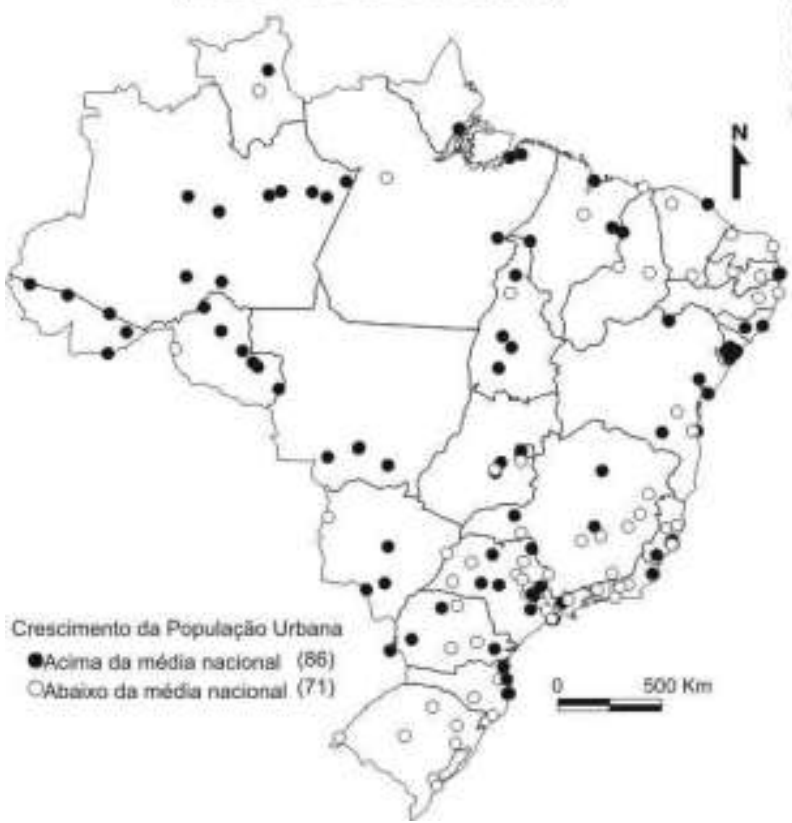

Fonte: FIBGE, Censo Demograifico de 2000. Laboratorio de Estudos Territoriais - IGCIUFMG

Cadernos do Leste 
A redução do peso da migração ocorre de forma generalizada, enquanto no primeiro período 81 localidades apresentavam menos de 15\% de população imigrante, em 2000 esse número sobe para 133. No entanto, entre as aglomerações da Região Norte, percebe-se ainda um alto número relativo de imigrantes: entre os municípios de Rondônia e Roraima e também no corredor rodoviário delimitado pela Belém-Brasilia, sobretudo no trecho do Tocantins. Os dados sugerem, portanto, o declínio de muitos dos fluxos migratórios nos últimos anos e o início de outros processos de ocupação e desenvolvimento do espaço urbano.

Entre as 86 localidades que apresentaram crescimento maior que a média nacional comparecem a maior parte dos pontos da Região Norte, além de algumas áreas de crescimento no entorno de algumas capitais nordestinas, no entorno da aglomeração metropolitana paulistana e também em direção as localidades do Centro-Oeste. Grande parte destas áreas com maior crescimento populacional apresentaram, também, maior participação de imigrantes na população total.

\section{4- MÉTODOS DE ANALISE DE REDES SOCIAIS APLICADOS AOS FLUXOS MIGRATÓRIOS NA REDE DE LOCALIDADES URBANAS}

Os métodos de análise de redes sociais permitem imprimir novas abordagens diante dos movimentos migratórios, tendo em vista que as características estruturais dos fluxos podem mostrar, com maior clareza, a contribuição econômico-demográfica das migrações na expansão dos centros urbanos brasileiros, bem como revelar algumas das conexões que dão formato a rede urbana atual.

A análise de redes sociais difere das formas convencionais de abordagem porque não centra atenção nos indivíduos e seus atributos, mas sim na possibilidade de existência de laços entre eles. Atributos individuais podem fornecer importantes informações sobre um subconjunto de atores em estudo, a partir de características próprias que conferem a estes maior importância dentro de um conjunto maior ${ }^{3}$. No entanto, dados desta natureza não são suficientes para mostrar um componente fundamental das redes: as relações (SOARES, 2002; FAZITO, 2002).

Um aspecto essencial da analise de redes sociais $\left(\boldsymbol{A} \boldsymbol{R} \boldsymbol{S}^{4}\right)$ é a natureza das informações a serem trabalhadas. Os dados relacionais são mais adequados do que dados de atributos, pois pressupõem a existência de pelo menos um par ordenando de atores que possuam uma

\footnotetext{
${ }^{3}$ Como por exemplo: indivíduos em um grupo especifico que possuam maiores níveis de renda, maior escolaridade, maior qualificação, que se localizem em posições estratégicas, etc.

${ }^{4}$ FAZITO (2002).
}

Cadernos do Leste

Artigos Cientificos

Belo Horizonte, Jan.-Dez. Vol.9, n9, 2009 
relação qualquer. Neste estudo, as localidades da rede serão os atores, enquanto os laços serão dados pelos fluxos migratórios.

Para representar esse tipo de dado a ARS se utiliza, entre outros recursos metodológicos, da álgebra de matrizes. As matrizes de origem/destino que representam a migração entre um conjunto de municípios podem ser utilizadas como fonte de dados para a ARS, pois permitem ao pesquisador trabalhar com uma série de medidas que descrevam aspectos estruturais da distribuição dos dados (SOARES, 2002).

Duas destas medidas serão apresentadas a seguir: A densidade e o Grau de Centralidade. Tais medidas, segundo SOARES (2002), integram dois grupos: a densidade faz parte das propriedades básicas de rede que se referem às relações entre a quantidade de laços e tamanho da rede. $\mathrm{O}$ grau de centralidade incorpora as medidas de centralização, que identificam atores que possuem posições estratégicas em função do estabelecimento de um grande número de relações ou então de relações privilegiadas com outros ${ }^{5}$.

Neste estudo algumas destas medidas de rede serão aplicadas a uma matriz de origem/destino, com o total de imigrantes dos pontos da rede em 1980 e 2000. As medidas de rede aqui apresentadas irão considerar apenas a existência ou não de relações entre as localidades, sem atribuir valores aos fluxos. Para tanto foram definidos, a partir de uma série de testes, um valor mínimo significativo para os mesmos, que equivale a marca de 50 pessoas ${ }^{6}$.

\section{- Tamanho e densidade (Density)}

O tamanho da rede refere-se a quantidade de atores e também aos possíveis laços que ela comporta. Em uma rede com dados direcionados, ${ }^{7}$ o número de pares ordenados pode ser calculado pela equação:

$$
N=K \cdot(K-1)
$$

Onde:

$\mathrm{N}$ - número de pares ordenados. $\mathrm{K}-$ número de atores na rede.

\footnotetext{
${ }^{5}$ A nomenclatura das medidas de rede em português foi utilizada a partir das traduções presentes em SOARES (2002).

${ }^{6}$ Para todos os pares ordenados que possuíam um valor de migrantes acima de 50 pessoas foi atribuído o valor 1 , e para todos os campos que possuíam menos de 50 migrantes, ou que não apresentavam trocas, foi atribuído o valor 0 . Este ponto de quebra nos dados - 50 pessoas - foi definido a partir de comparações com a densidade das relações presentes em matrizes binarizadas a partir de diversos valores. A versão com 50 pessoas apresentou variância semelhante a pontos de quebra de até 300 pessoas, sendo então uma marca confiável para expressar a estrutura de fluxos significativos. Esta limitação ocorre em função de que a maioria das medidas de rede só podem ser utilizadas para dados binarizados.
}

${ }^{7}$ Dados que apresentem sentido nos fluxos. Assim, os valores do par ordenado $(\mathrm{a}, \mathrm{b})$ são diferentes dos valores de (b,a). 
A rede de localidades centrais aqui examinada, compunha-se de 157 pontos em 1980 e 165 em 2000. Em 1980 havia 24.492 laços diretos possíveis entre as localidades dados pela migração interna, e em 2000 esse número cresce para 27.060. Tendo em consideração a extensão territorial do país, esses valores expressam o grande potencial de conexões que uma rede urbana tão ampla pode gerar. As opções de destino para os fluxos migratórios são diversas mesmo considerando somente as localidades mais dinâmicas do território.

A densidade é calculada a partir da razão entre o número de laços presentes e os laços possíveis na matriz, e demonstra o nível de conexões existentes, bem como a integração total da rede. Os valores apresentados nos dois anos mostram que o nível de coesão ainda é muito baixo considerando o número de laços possíveis. Contudo houve um importante aumento nas ligações no período 1980-2000.

Em 1980 a densidade da rede foi de 0,12, ou seja 12\% dos laços possíveis estavam presentes, o que representava 2.939 ligações entre as localidades por fluxos migratórios expressivos. Em 2000 observa-se um aumento de 3\% na quantidade de laços entre os pontos totalizando 4.143 ligações. Em 1980 e 2000 a rede apresentou níveis baixos de densidade, não obstante a existência de vários subgrupos ou frações da rede. Os valores de desvio padrão $(0,33$ em 1980 e 0,35 em 2000) indicaram uma variabilidade muito grande nos níveis de conexão dos pontos.

Os dados demonstram que a integração territorial da rede em estudo ainda pode ser muito desenvolvida. O processo recente de desconcentração espacial provavelmente já deu início a um movimento de integração dos subespaços permitindo a formação de novas áreas de articulação no território, principalmente tendo em conta que os oito municípios agregados a rede de 2000 estão na Região Norte, que, como já mostraram os dados, configura uma área de expansão populacional.

\section{- Grau de Centralidade (Centrality Degree)}

As medidas de centralidade geralmente associam-se a ideia de distribuição de poder dentro da rede, considerando que o poder é uma característica que emerge de relações. Atores não possuem poder individualmente, mas esse é resultado da capacidade de dominar ou influenciar outros. Desta maneira, atores mais centrais na rede são detentores de maior poder entre os nós, e tal centralidade pode ser apreendida a partir do número de laços eficientes que um ator é capaz de possuir (HANNEMAN, 2000).

A existência de muitos vínculos pode tornar o ator cada vez menos dependente de outros, possibilitando o acesso a um maior conjunto de recursos da rede. Por outro lado à existência de um grande número de conexões também capacita ao ator intermediar relações entre outros, conferindo a este posição estratégica (SOARES, 2002). 
A medidas aqui utilizada será o grau de centralidade, que calcula o número de atores com os quais um ator-fonte possui vínculos diretos. Em dados direcionados, esta medida calcula a centralidade para os fluxos de entrada e saída. Esta diferenciação é importante na medida em que revela se os papéis estruturais dos atores na rede são os mesmos para entrada e saída de fluxos. Atores que recebem muitos laços revelam possuir alto prestígio entre os outros, já os atores que enviam muitos laços são mais influentes (SOARES, 2002).

A Figura 2 traz os valores do grau de centralidade para as localidades da rede em 1980 e 2000 nos fluxos de saída e entrada. Os dados de 1980 mostram que as localidades da rede se diferenciavam significativamente entre si na capacidade de centralização tanto na emigração como na imigração. As localidades da Região Norte mostram alguma centralização somente para os fluxos de entrada de migrantes, principalmente no Estado de Rondônia.

Ao que parece, a característica de área de povoamento atribuía a estes locais um maior número de ligações diretas na atração de população. $\mathrm{Na}$ Região Nordeste já se percebe uma maior concentração de localidades mais centrais na saída de migrantes, tornando evidente alguns processos migratórios que ainda se estabeleciam enfaticamente nesta região, e que incluíam a maior parte das aglomerações.

Já em 2000 os dados demonstram que esse processo sofre algumas alterações decorrentes das mudanças nos padrões dos movimentos migratórios já observados. A região Norte ainda permanece como uma área de baixa centralidade, a exceção das localidades de Rondônia, que neste período estabelecem um número elevado de laços diretos tanto na entrada como na saída de imigrantes.

As localidades do interior do Estado de São Paulo também apresentaram um aumento na sua centralidade, bem como se percebe um eixo de localidades no Centro-Oeste brasileiro, que, em ambos os períodos, mantiveram maior centralidade, sendo formado pelos municípios de Dourados, Campo Grande (em Mato Grosso do Sul), Rondonópolis, Cuiabá e Várzea Grande (em Mato Grosso). 
Figura 2

Grau de centralidade das localidades da rede nos
fluxos de saída e entrada

Trocas Migratórias na rede em 1980
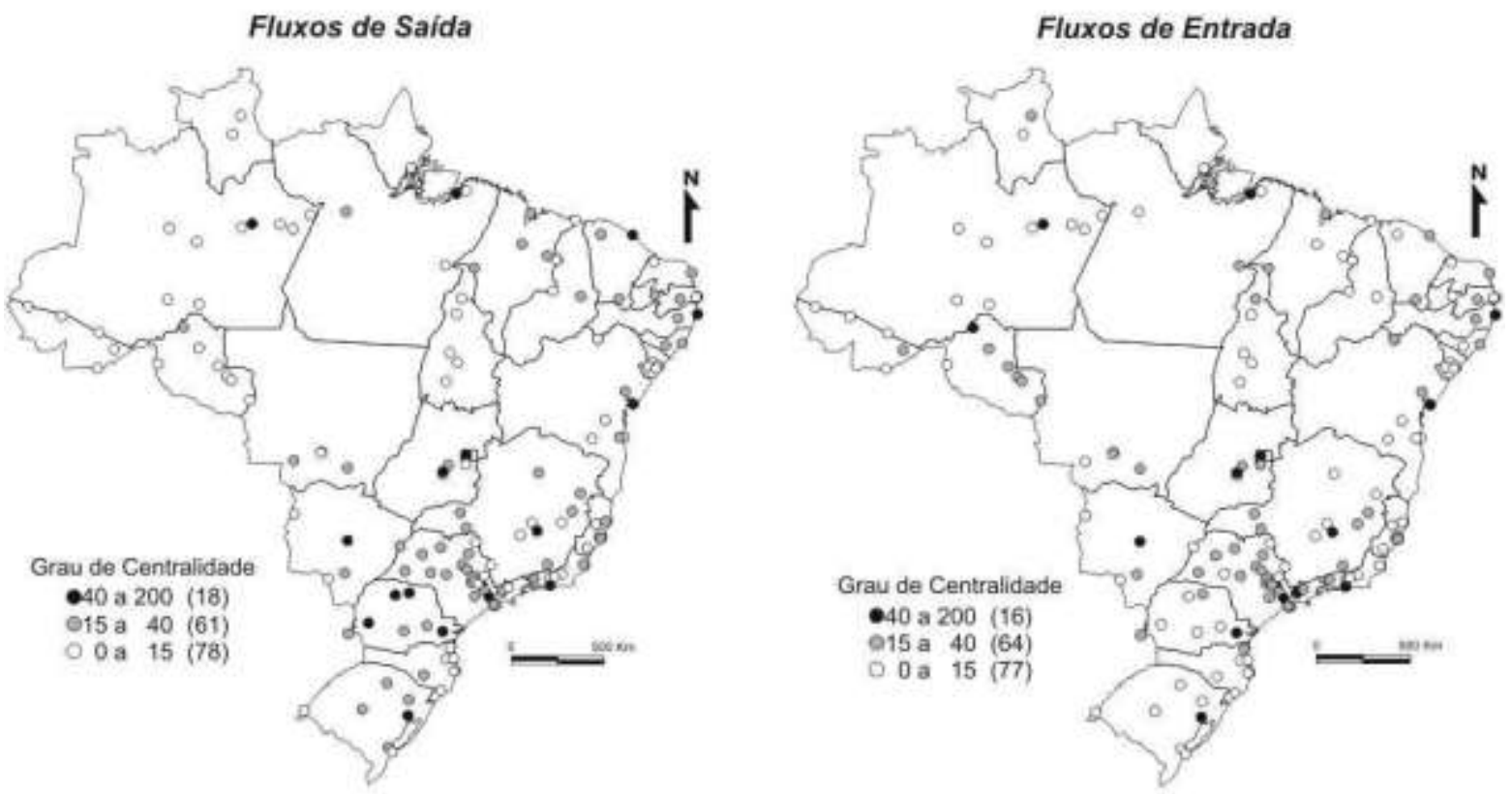

Trocas Migratórias na rede em 2000
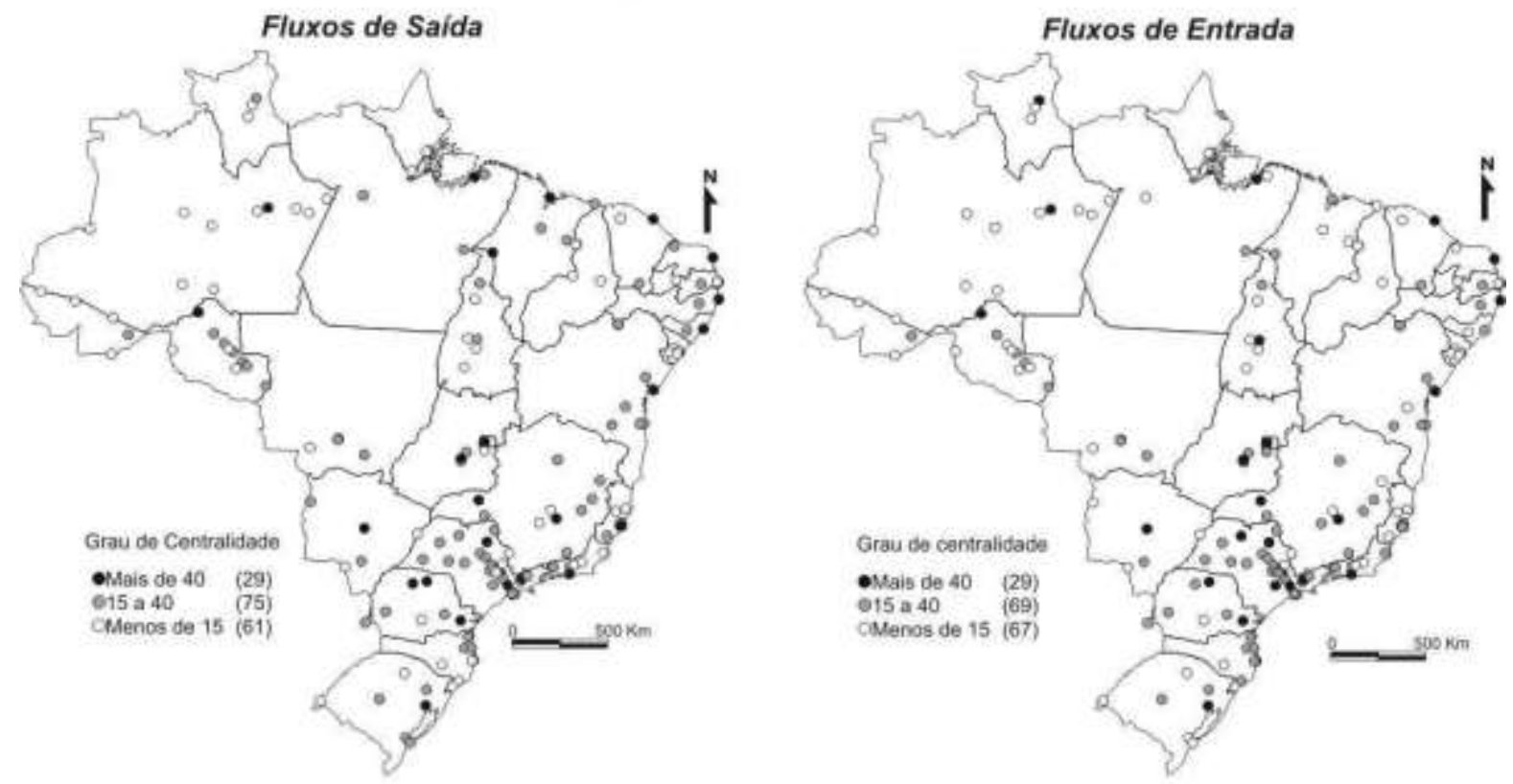

Fonte: FIBGE, Censo Demografico de 2000

Elaboraç3: BRAGA, Fernando MATOS Rallo

Laboratónio de Estudos Territoriais - IGCIUFMG 


\section{5 - OCUPAÇÃO E RENDA NAS TROCAS MIGRATÓRIAS}

Como a rede apresentou um aumento na sua integração territorial, mesmo com a redução na participação dos imigrantes na população total observada no período, pode-se avaliar mais profundamente a contribuição da imigração para o desenvolvimento das novas áreas que se integram ao conjunto de fluxos presentes na rede.

As analises anteriores avaliaram a condição estrutural dos fluxos na rede a partir dos movimentos migratórios significativos revelando importantes características das conexões entre os pontos. Entretanto, se os imigrantes fossem classificados segundo variáveis socioeconômicas como ocupação e renda, quais diferenças poderiam ser encontradas nas comparações entre as trocas migratórias em 1980 e 2000 ?

Para as mesmas medidas aplicadas anteriormente foram submetidas matrizes de fluxos em 1980 e 2000 classificando a população migrante segundo ocupação e renda. No primeiro aspecto foram considerados todos os imigrantes da População Economicamente Ativa que exerciam algum trabalho remunerado na data de referência do censo. Para renda foram considerados os migrantes que auferiam ganhos iguais ou superiores a dois salários mínimos ${ }^{8}$. Desta maneira as medidas a seguir consideram as trocas migratórias expressivas ${ }^{9}$ entre as localidades da rede segundo a inserção no mercado de trabalho e a renda da população.

Como já mencionado anteriormente, atributos individuais mostram-se incompletos diante de uma abordagem relacional, característica essencial da análise de redes sociais. No entanto, é certo que atributos influenciam diretamente as relações. Portanto, torna-se pertinente introduzir determinados dados que qualifiquem melhor os fluxos migratórios, em especial aqueles capazes de impactar as estruturas de relações da rede, inclusive apontando tendências e novos padrões nas articulações entre população e espaço.

\section{- Densidade}

Os dados de densidade já demonstraram que houve aumento da integração na rede no período 1980-2000. Entretanto isto torna-se mais claro quando a situação dos imigrantes no mercado de

\footnotetext{
${ }^{8}$ Esse valor foi considerado porque se aproxima da renda mediana dos chefes de domicilio no ano de 2000 segundo dados do IBGE (www.sidra.ibge.gov.br).

${ }^{9}$ Para a aplicação das medidas de redes sociais as matrizes necessitaram ser binarizadas assim como no caso anterior. No entanto, devido a redução nos montantes populacionais provocada pelos cortes na população o valor de quebra considerado para fluxos migratórios expressivos foi reduzido para 25 pessoas.
} 
trabalho é melhor qualificada. A tabela 1 mostra que as trocas entre os migrantes ocupados em 1980 representam 10\% do total possível de trocas, enquanto em 2000 a mesma relação alcança 14\%, esse diferencial significa um total de 1.153 ligações a mais. Quanto à renda, percebe-se, principalmente pela exclusão dos indivíduos com ganhos até um salário, que a densidade da rede sofre uma forte diminuição. Os dados novamente indicam que em 1980 a integração da rede era sensivelmente menor se consideradas a distribuição dos migrantes que auferiam renda. As trocas de migrantes com renda igual ou acima de dois salários mínimos alcançavam somente 7\% do total de trocas possíveis na rede. Já em 2000, mesmo com uma diminuição também expressiva dos valores, estes ainda se mantêm acima de $10 \%$.

Os valores de desvio padrão, tanto em 1980 quanto em 2000, próximos a 0,30, mostram que as conexões na rede continuam muito dispersas, ou seja, há blocos de localidades que mantém alta integração enquanto outros se conectam com poucos pontos.

Novamente percebe-se que o grande potencial de adensamento da rede, ainda pouco explorado. Os dados, contudo, demonstram estar acontecendo alterações positivas nas últimas duas décadas. A medida que os fluxos migratórios fazem aumentar o nível de integração da rede, as localidades se interligarem em número maior, criando possibilidades para o desenvolvimento socioeconômico. Tais avanços são mais significativos se os imigrantes contribuírem positivamente com as economias das localidades onde se estabelecem.

\section{Tabela 1}

\section{Densidade de trocas migratórias na rede de localidades centrais do Brasil em 1980 e 2000}

\begin{tabular}{|c|c|c|c|c|}
\hline & \multicolumn{2}{|c|}{ Rede 1980} & \multicolumn{2}{|c|}{ Rede 2000} \\
\hline $\begin{array}{l}\text { Medidas de } \\
\text { Rede }\end{array}$ & Ocupados ${ }^{1}$ & Renda $^{2}$ & Ocupados $^{1}$ & Renda $^{2}$ \\
\hline Densidade & 0,108 & 0,071 & 0,140 & 0,104 \\
\hline Desvio Padrão & 0,31 & 0,26 & 0,35 & 0,31 \\
\hline $\mathbf{N}^{\circ}$ de Trocas & 2.638 & 1.732 & 3.791 & 2.803 \\
\hline
\end{tabular}




\section{- Grau de Centralidade}

O grau de centralidade pode ajudar a perceber melhor as contribuições dos imigrantes em cada uma das localidades da rede, já que apresenta o número de conexões diretas de cada ator. O aumento de porções nas quais as localidades estabelecem mais opções de envio e recepção de migrantes, que seriam capazes de ingressar no mercado de trabalho competitivamente, abre possibilidade para inúmeras relações entre os centros, baseadas na potencialidade material que os migrantes levam consigo em seus movimentos.

A Figura 3 apresenta o grau de centralidade na rede de localidades segundo as trocas migratórias em 1980 e 2000 envolvendo migrantes ocupados. Na Região Norte, em 1980, somente as capitais estaduais e alguns municípios de Rondônia apresentavam alguma expressão nas trocas, sobretudo na entrada de migrantes. A capacidade de atração e manutenção de correntes migratórias direcionadas aos centros urbanos mais importantes se afigurava muito restrita. Já na Região Nordeste, notava-se que a capacidade de centralização das localidades, em face da baixa capacidade de absorver população com trabalho remunerado, resumia-se, em grande parte, ao envio de migrantes. Contudo, merece destaque, ainda em 1980, a situação de alguns municípios do oeste paulista e norte do Paraná que aparecem mais bem articulados na saída da população, indicando, inclusive, conexões com fluxos de entrada na Região Norte.

Em 2000, os mapas mostram que a capacidade da maioria áreas de enviar e receber migrantes tornou-se mais próxima numericamente, condição esta que pode ser observada, por exemplo, nas localidades da rede urbana de Rondônia e também nos pontos da rede que compreendem a área de grande densidade que se estende desde o norte do Paraná até Goiânia-Brasília. É bem verdade, que na Região Nordeste, as cidades ainda se articulam com um número maior de outras na saída, mas já se percebe alguma alteração nestas condições, considerando o aumento no grau de centralidade nos fluxos de entrada nas capitais estaduais.

Entre as localidades que ampliaram significativamente o número de conexões no período de 20 anos, ou seja, que estabeleceram mais de 40 laços diretos nas trocas migratórias com as localidades da rede, merecem destaque nos laços de saída de migrantes, nas Regiões Norte e Nordeste, Porto Velho, Manaus, RM de Belém, Imperatriz, São Luís, Teresina, Natal, João Pessoa, Maceió e Aracaju. Já em relação à entrada, além de algumas capitais nordestinas (RMs de Fortaleza e Recife e Natal), algumas cidades das Regiões Sudeste e Sul também se destacam com o incremento de suas articulações, como Uberlândia, Vila Velha, Ribeirão Preto, São Jose do Rio Preto, Londrina, Florianópolis e RM de Porto Alegre. 
Se a evolução da rede expressa, com clareza, o surgimento de novas áreas articuladas dentro do sistema urbano brasileiro, nas quais os migrantes que trabalham devem contribuir positivamente nas localidades receptoras, o que dizer de porções da rede dotadas de centralidade nas trocas de migrantes exibindo maiores níveis renda? É possível que nas regiões que enviem e recebam tais migrantes as articulações entre as localidades sejam um canal de trocas a partir do qual ganhos econômicos e sociais vinculem regiões de origem e destino. 
Figura 3

Grau de centralidade das localidades da rede nos fluxos de saída e entrada segundo migrantes ocupados

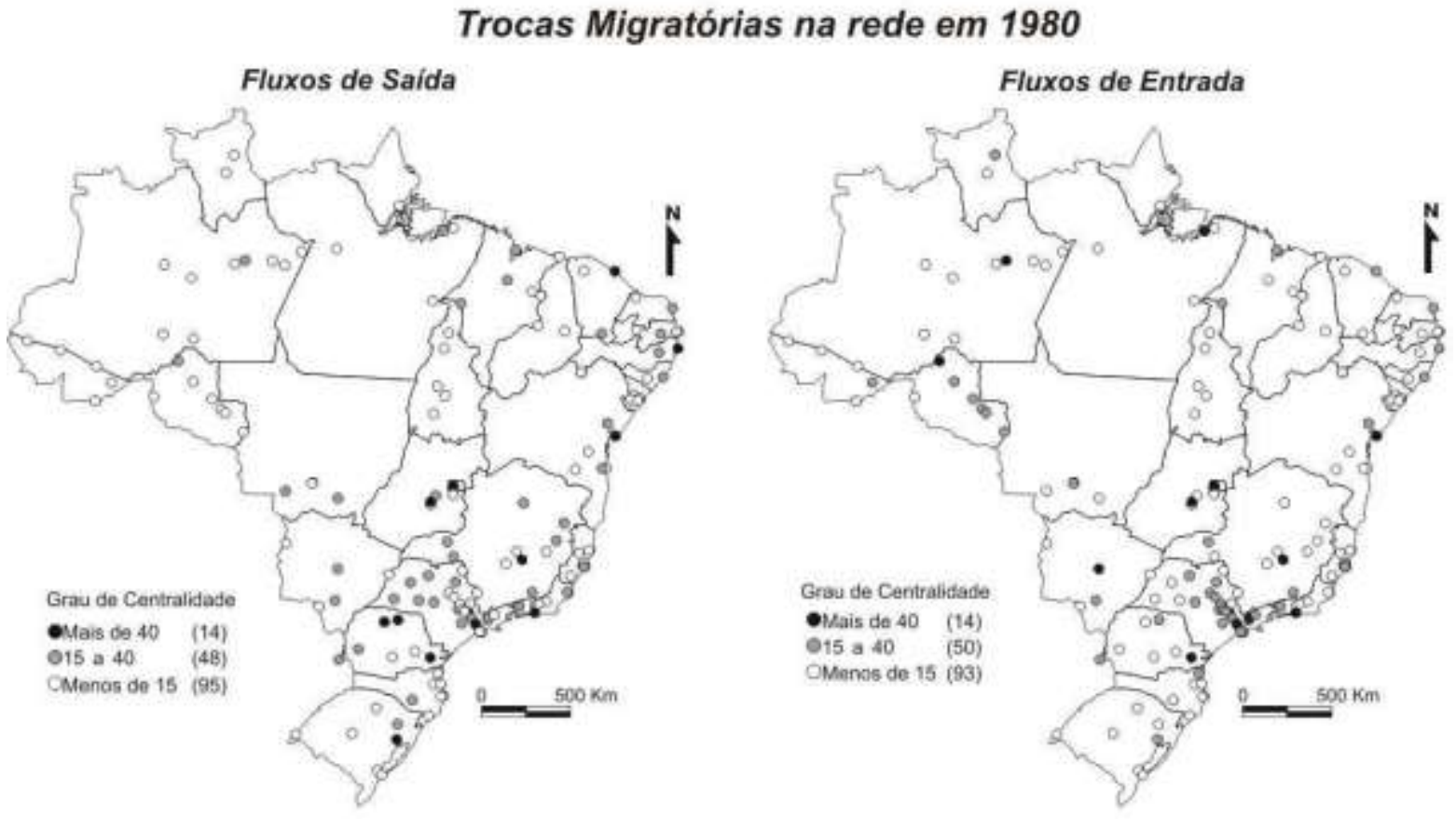

Trocas Migratórias na rede em 2000
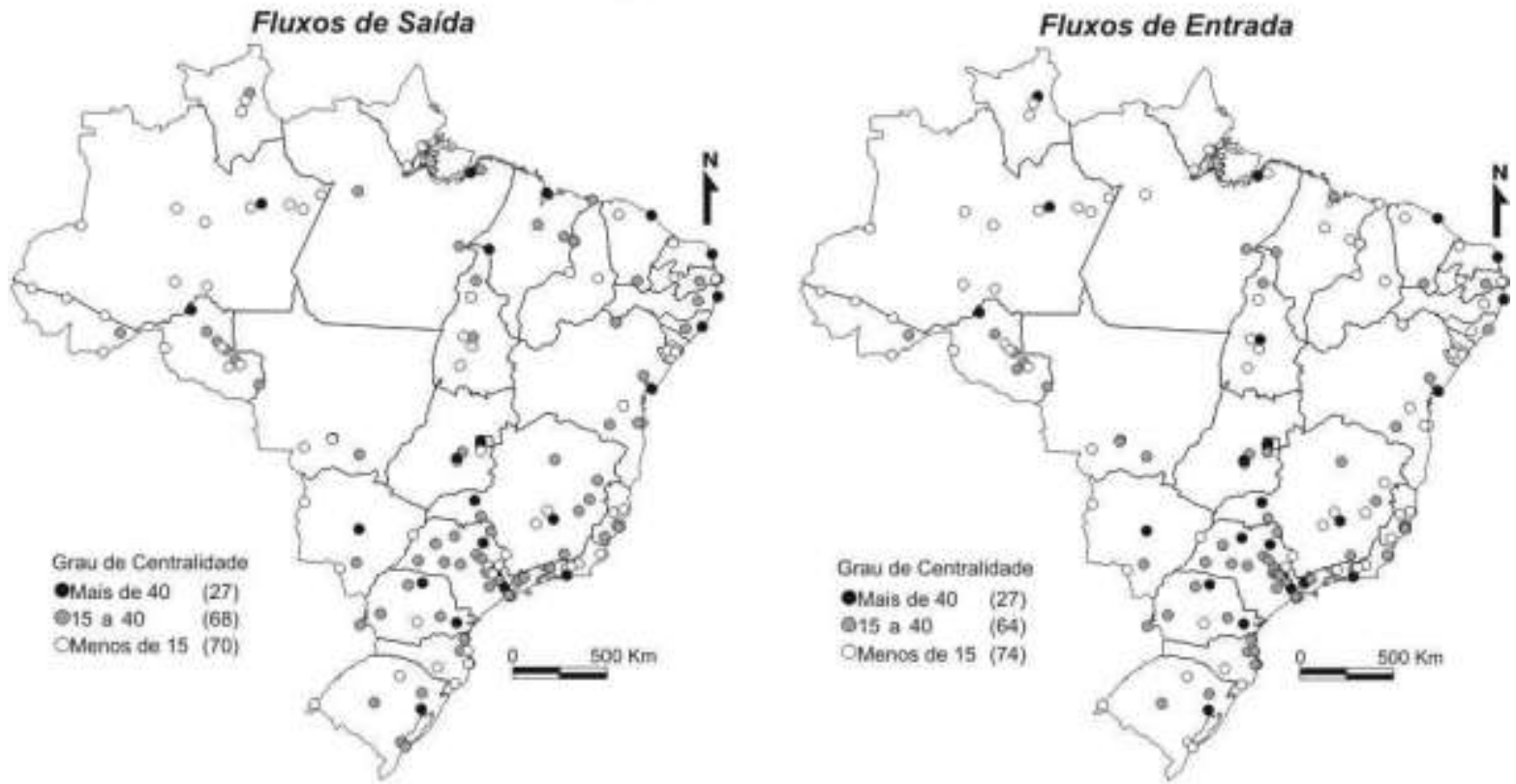

Fonte: FIBGE, Censo Demográfico de 2000

Elaboraciào; BRAGA. Fernando MATOS, Ralfo

Laboratório de Estudos Territoriais - IGCIUFMG 
A Figura 4 inicia esta discussão mostrando o grau de centralidade nas localidades da rede a partir das trocas populacionais com migrantes que recebem dois ou mais salários mínimos. Em 1980 percebe-se que a rede possuía uma pequena integração, considerando que cerca de 120 localidades, entre as 157, apresentavam baixo grau de centralidade (menos de 15) tanto na entrada como na saída de migrantes. As áreas em que aglomeravam pontos com maiores valores de centralidade estavam no eixo Norte do Paraná/Goiânia-Brasília, além das capitais estaduais, dispersas territorialmente.

Os dados indicam que em 1980 havia uma concentração elevada das oportunidades de boa remuneração em pouquíssimas localidades, e isso fazia com que as redes sociais da migração gerassem um número pequeno de fluxos contínuos na rede urbana. Alta centralidade havia somente nas capitais estaduais e na hinterlândia da RM de São Paulo, no que se refere às oportunidades de trabalho dos imigrantes.

Em 2000, os mapas mostram que os eixos de maior articulação presentes nos fluxos migratórios da rede comparecem também entre as trocas com migrantes melhor remunerados, a exemplo do eixo Norte do Paraná/Goiânia-Brasília, das localidades de Rondônia e Tocantins, além de trechos da franja litorânea no Nordeste. Nos fluxos de saída percebe-se um aumento nas conexões em localidades como Manaus e as RMs de Belém e Fortaleza, além das cidades de Ribeirão Preto, Campo Grande e Cuiabá. Já entre os fluxos de entrada, além das capitais nordestinas, observa-se aumento significativo das conexões de cidades como Campinas, São José dos Campos, Florianópolis, Campo Grande e Goiânia.

Ao que tudo indica, durante esses vinte anos, a rede acumulou, a partir da integração territorial e dos processos de desconcentração espacial, maior interconectividade entre os fluxos migratórios. Os dados mostram que se multiplicaram as localidades capazes de estabelecer laços com outras, recebendo e enviando migrantes com melhores níveis de remuneração. Esse fato traz em si implicações sobre os esforços voltados a redução das desigualdades socioespaciais e do isolamento de subespaços urbanos do País, ampliando com isso os níveis de equidade inter-regional.

\section{- Manchas síntese da integração territorial na rede}

As medidas até aqui aplicadas demonstraram um nível considerável de aumento na integração territorial da rede, em face do crescimento das opções de destino para os fluxos migratórios, os quais alimentam a capacidade de centralização de vários subespaços em expansão.

Reconhecer melhor tais subespaços e avaliar sua evolução na rede de localidades entre 1980 e 2000 é o objetivo subsequente. Isto pode ser obtido por meio de mapas que superponham informações seletivas sobre renda e instrução, exprimindo-as por meio de "manchas" que 
sintetizem, grosso modo, o processo de integração territorial no Brasil contemporâneo. A Figura 5 apresenta estas manchas a partir dos fluxos migratórios envolvendo migrantes ocupados da PEA e com níveis de renda acima da mediana nacional. Os resultados mapeados utilizaram como critério, primeiramente, a existência de uma aglomeração de pontos, ou seja, de localidades relativamente próximas umas das outras, configurando, assim, uma espécie de região relevante quanto aos fluxos migratórios. O critério considerado foi à expressão do grau de centralidade em tais conjuntos, tanto nos fluxos de saída como nos de entrada. 
Figura 4

Grau de centralidade das localidades da rede nos fluxos de saída e entrada segundo migrantes com renda igual ou acima de 2 salários minimos

Trocas Migratórias na rede em 1980
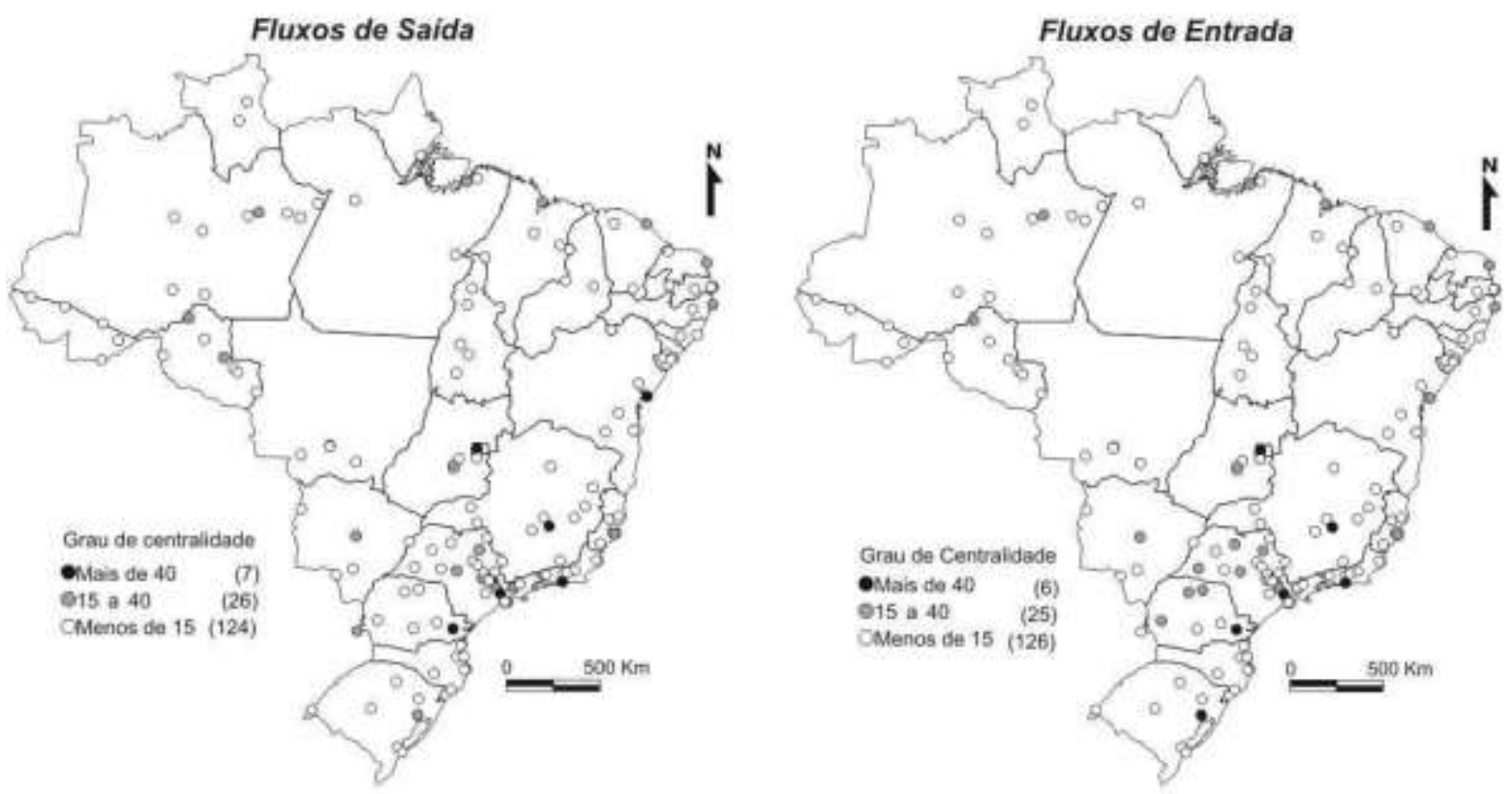

Trocas Migratórias na rede em 2000
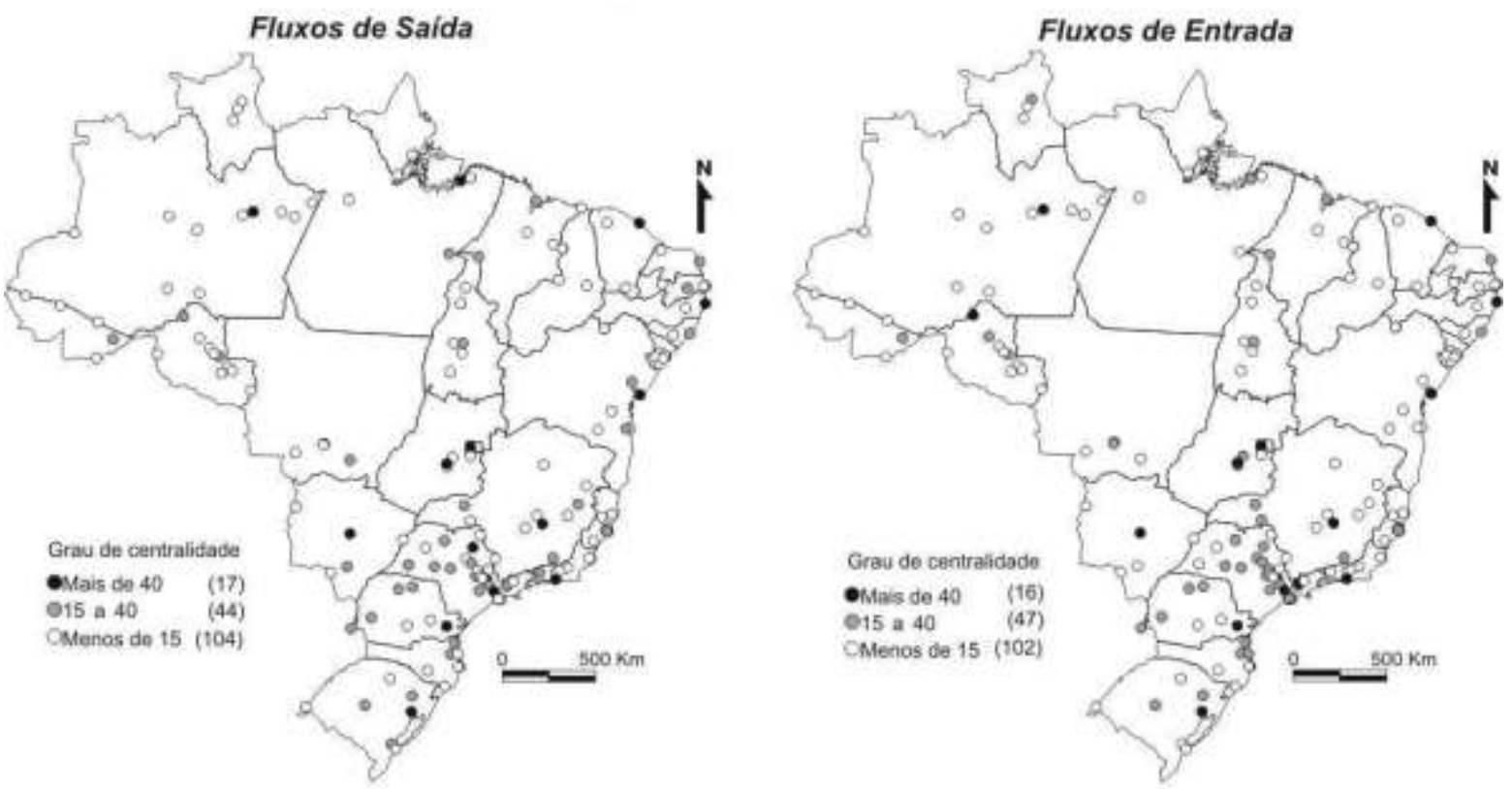

Fonte: FIBGE, Censo Demográfico de 2000

Elaboraçảo: BRAGA, Fernando. MATOS, Ralfo

Laboratório de Estudos Territoriais - IGCIUFMG 
Figura 5

Manchas sítese da integração territorial na rede a partir das trocas migratórias em 1980 e 2000.
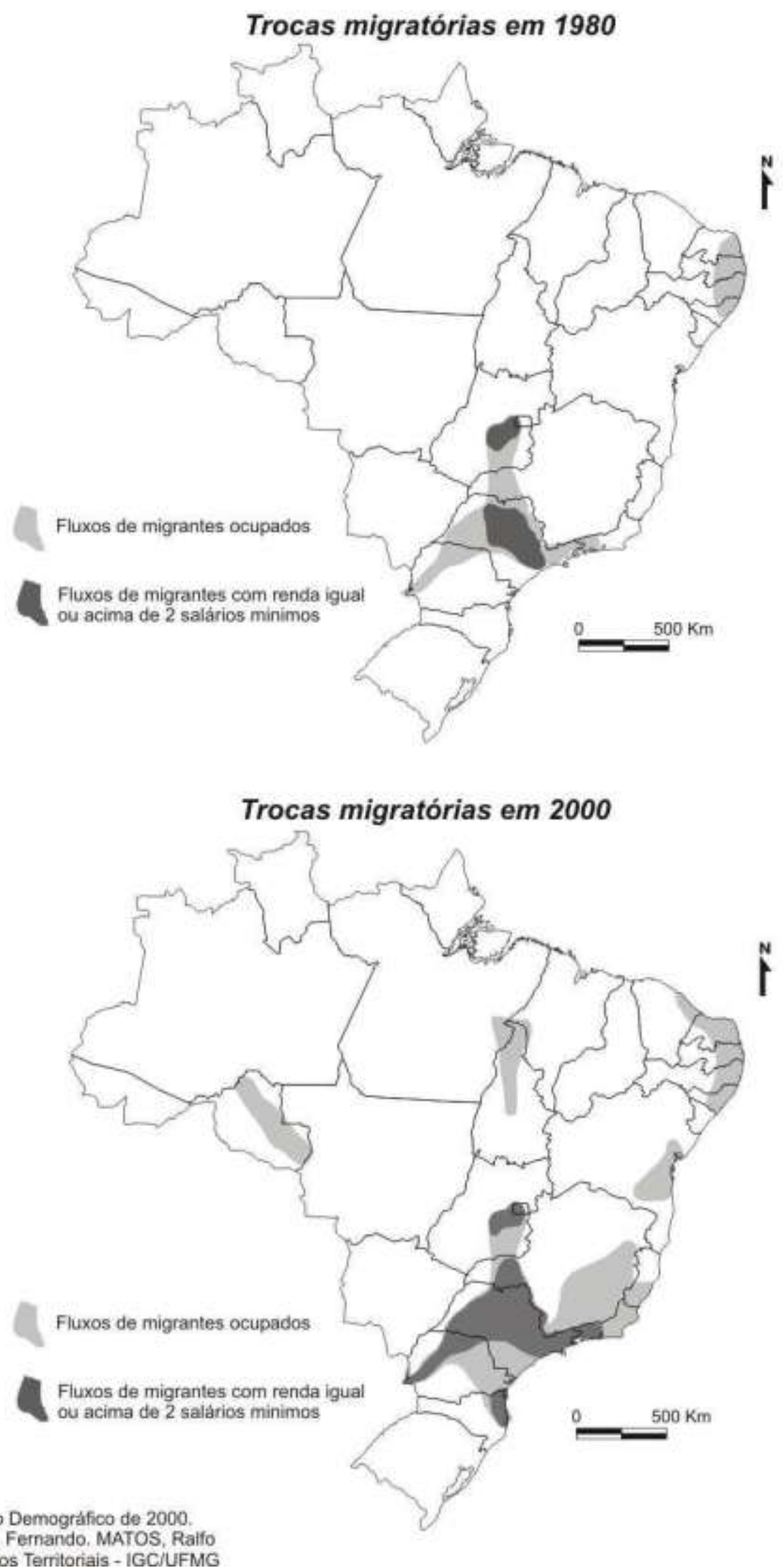

Fonte: FIBGE, Censo Demografico de 2000.

Elaboraçðð०: BRAGA, Fernando, MATOS, Raifo

Laboratório de Estudos Territoriais - IGCIUFMG 
Em 1980, as áreas de maior articulação na rede são bem restritas, como já examinado. As localidades de maior centralidade nos fluxos de migrantes ocupados restringem-se somente a duas áreas em todo o Brasil: uma pequena faixa no litoral nordestino, onde se destacam a centralidade de Natal, Recife e Maceió, e outra mancha, que cobre a grande área que se estende desde o norte do Paraná até Brasília-Goiânia, sendo controlada pelas RMs de São Paulo e Rio de Janeiro. Essa mancha destaca a única grande porção da rede que estabelece um número considerável de conexões com o restante dos pontos.

Ao considerar a mancha gerada pelos fluxos de migrantes com renda igual ou superior a dois salários mínimos, as áreas que apresentam algum dinamismo se reduzem consideravelmente. $\mathrm{Na}$ verdade, somente a hinterlândia mais próxima da RM de São Paulo e o eixo Brasília-Goiânia apresentam um aglomerado de localidades notáveis. As manchas mostram afinal como a capacidade de centralização das localidades era rarefeita e extremamente concentrada na região de maior adensamento urbano do país.

Em 2000, as manchas apresentadas explicitam melhor o crescimento de subespaços da rede fortemente articulados, bem como o surgimento de novas áreas nas quais a aglomeração de localidades já dispõe de um número mais significativo de ligações. As trocas entre migrantes ocupados definem um conjunto de cinco manchas em todo o território. No litoral nordestino, além do crescimento da mancha já existente em 1980, incluindo a RM de Fortaleza, outra aglomeração também apresentou maior centralidade nas suas trocas: a área que se estende da RM de Salvador até o eixo Ilhéus-Itabuna. Já na Região Norte dois subespaços se destacam, o relativo ao arco oeste de Rondônia, que em 2000 apresenta maiores articulações com a rede tanto na entrada como na saída de migrantes (evoluindo da importância restrita a entrada, como que ocorria em 1980), e também alguns pontos no Estado do Tocantins, que estruturam um eixo rodoviário que articula os núcleos populacionais do centro-sul com e norte dopaís.

A última mancha, apenas parcialmente delineada em 1980, denota em 2000 a expansão da urbanização sudestina, em espaços muito bem articulados, que, inclusive dão suporte processo recente de desconcentração espacial da população. Além do eixo norte do Paraná/Brasília-Goiânia integram esta mancha localidades de Minas Gerais, Rio de Janeiro e Espírito Santo, e ainda as aglomerações no entorno da RM de Curitiba e Florianópolis. É também nesse espaço que as manchas relativas às trocas de migrantes ocupados com renda igual ou superior de 2 salários mínimos comparecem expressivamente. Aliás, os dados indicam que houve uma sensível expansão espacial dessa condição econômica em relação a 1980, por meio da inserção de localidades no Rio de Janeiro, Paraná e Santa Catarina. 
Os procedimentos de análise aqui adotados e a espacialização por meio de manchas notáveis permitiram concluir que os dados censitários sobre migrações internas são ricos de possibilidades, sendo, inclusive, capazes de evidenciar níveis de integração de mão-de-obra migrante no mercado de trabalho em ocupações remuneradas, indicando o surgimento de novos subespaços articulados em rede que devem estar colaborando com o aumento da integração territorial das áreas urbanas do País.

\section{CONSIDERAÇÕES FINAIS}

Dado um conjunto de localidades centrais, cujos critérios de definição procuram, de uma forma simplificada, identificar as áreas urbanas mais significativas do País em termos de tamanho populacional, pode-se aplicar sobre ele um elenco de medidas derivadas da ARS (Análise de Redes Sociais) ajustadas a dados de migração intermunicipal.

Os resultados da aplicação dessas medidas reuniram evidências de que o processo de dispersão dos fluxos migratórios vem acompanhado pelo aumento das articulações em muitos pontos da rede. Ou seja, as localidades da rede, de um modo geral, mesmo com a redução de participação dos imigrantes na população total nos últimos vinte anos, estruturaram um número maior de ligações entre si, exprimindo avanços na integração das áreas urbanas brasileiras. Tanto a densidade como o grau de centralidade assinalaram que a estrutura dos fluxos na rede urbana tornou-se mais dinâmica, em decorrência do surgimento de novos espaços, antes isolados na rede, os quais passaram a operar como transmissores de recursos humanos e materiais. A diversificação e facilitação dos movimentos na origem e no destino é um corolário dessas evidências.

A existência de uma rede urbana com alto potencial de adensamento certamente constitui instrumento de política pública aplicável à redução das desigualdades econômicas e sociais. A multiplicação de centros de grande e médio porte em todo o país, por definição, abre possibilidades de acesso a melhores condições de vida para muita gente, o que por sua vez, contribui com a diminuição da excessiva concentração urbana do País. E isso já vem ocorrendo no Brasil das últimas décadas. Os dados de ocupação e renda aqui trabalhados confirmaram tais hipóteses, indicando que o aumento do número de centros bem articulados econômica e socialmente, relaciona-se à expansão de oportunidades de trabalho.

Entretanto, convém ressaltar que o aumento da integração ainda é pequeno, considerando todo o potencial da rede urbana. Enquanto as trocas de migrantes ocupados já deixam marcas de dinamismo em algumas porções do território brasileiro, os migrantes com melhores níveis 
de renda ainda circulam dentro de um restrito número de pontos da rede, quase sempre referidos a áreas historicamente mais dinâmicas. Mesmo com as indicações de reversão dos processos reprodutores de deseconomias de aglomeração, o espaço de intervenções públicas corretivas e indutoras de eficiência espacial é ainda bastante amplo, sobretudo se vier acompanhado de medidas promotoras de equidade regional, mas que utilizem-se do paradigma das redes, como um novo instrumento adequado à seleção de fatores de desenvolvimento econômico, implantação de infraestruturas e investimentos sociais que colaborem para a inclusão de trabalhadores que tornaram-se redundantes na economia capitalista dos dias de hoje. 


\section{REFERÊNCIAS BIBLIOGRÁFICAS}

AMORIM e SERRA. Evolução e perspectivas do papel das cidades médias no planejamento urbano e regional. In:ANDRADE e SERRA (org.) Cidades Médias Brasileiras. Rio de Janeiro: IPEA, 2001

ANDRADE e SERRA. O desempenho das cidades médias no crescimento populacional brasileiro no período 1970/2000. In: ANDRADE e SERRA (org.) Cidades Médias Brasileiras. Rio de Janeiro: IPEA, 2001

BAENINGER, Rosana. Migrações Internas no Brasil: Municípios metropolitanos e nãometropolitanos. Anais do II Encontro Nacional sobre migração. Belo Horizonte: Abep. 2000. p. 535562.

BRADFORD, M. G.; KENT, W. Geografia Humana: Teoria e suas Aplicações. Lisboa: Gradativa. 1977

CLARCK, David. A localização urbana e o sistema urbano in Introdução a Geografia Urbana. Rio de Janeiro: Bertrand Brasil. $2^{\circ}$ Ed. 1982. p. 127-181.

CORREA, Roberto Lobato. A Rede Urbana. São Paulo: Ática. 1994 Trajetórias Geográficas. Rio de Janeiro: Bertrand Brasil. 1997.

CUNHA, Jose Marcos Pinta da. Aspectos Demográficos da Estruturação das Regiões Metropolitanas Brasileiras. In HOGAN, BAENINGER, CUNHA, CARMO (org.). Migração e Ambiente nas Aglomerações Urbanas. Campinas: Unicamp, 2001. p.19-49.

DEFFONTAINES, Pierre. Como se constitui a rede de cidades no Brasil. Boletim Geográfico, Rio de Janeiro, v. 2, n. 14, pt. 1, p. 141-148, maio1944.

FAZITO, Dimitri. A Análise de redes sociais (ARS) e a migração: mito e realidade. Anais do XIII Encontro Nacional de Estudos Populacionais. Ouro Preto: ABEP, 2002.

FUSCO, Wilson. Redes Sociais na Migração internacional: O caso de Governador Valadares. Anais do II Encontro Nacional sobre migração. Belo Horizonte: Abep. 2000. p. 317-342.

GEIGER, Pedro Pinchas. Observações sobre a organização urbana no Brasil, in Evolução da Rede Urbana Brasileira. Instituto Nacional de Estudos Pedagógicos: Rio de Janeiro, 1963.

HANNEMAN, Robert. Introducción a los métodos del análisis de redes sociales. 2000. Disponível em: < http://wisard.ucr.edu/ rhannema/index.htm\# news $>$. Acesso em Setembro de 2003.

MATOS, Ralfo. A contribuição dos imigrantes em áreas de desconcentração demográfica do Brasil contemporâneo. Revista Brasileira de Estudos Populacionais. Campinas, V.19. nº 1. jan/jun 2002. P.49- 74.

MATOS, Ralfo e BRAGA, Fernando. Rede Urbana e redistribuição espacial da população brasileira. Anais do XIII Encontro Nacional de Estudos Populacionais. Ouro Preto: ABEP, 2002.

MONBEIG, Pierre. Aspectos Geográficos do Crescimento de São Paulo. Boletim Geográfico, Rio de Janeiro, v.12, n. 19, mar. -abr. 1954. 
PACHECO, Carlos Américo; PATARRA, Neide. Movimentos Migratórios no Anos 80: Novos Padrões?. Anais do I Encontro Nacional sobre migração. Curitiba: IPARDES, FNUAP. 1998. p. 463478.

SANTOS, Milton. A Urbanização Brasileira. São Paulo: Hucitec. 1993. p.17-29.

SINGER, Paul. Economia Política da Urbanização. São Paulo: Editora Brasiliense. 10º ed. 1985.

SOARES, Weber. Da metáfora a substância: Redes Sociais, Redes Migratórias e Migração nacional e internacional em Valadares e Ipatinga. Belo Horizonte:

CEDEPLAR/UFMG. 2002. (tese de doutorado) 